\title{
The Association of Vitamin D Status and Vitamin D Replacement Therapy with Glycemic Control, Serum Uric Acid Levels, and Microalbuminuria in Patients with Type 2 Diabetes and Chronic Kidney Disease
}

\author{
Savas Sipahi ${ }^{\mathrm{a}}$ Seyyid Bilal Acikgoz ${ }^{\mathrm{b}}$ Ahmed Bilal Genc ${ }^{\mathrm{b}} \quad$ Mehmet Yildirim $^{\mathrm{b}}$ \\ Yalcin Solak ${ }^{a}$ Ali Tamer ${ }^{b}$ \\ ${ }^{a}$ Division of Nephrology, Department of Internal Medicine and ${ }^{\mathrm{b}}$ Department of Internal Medicine, Faculty of Medicine, \\ Sakarya University, Sakarya, Turkey
}

\section{Keywords}

Type 2 diabetes - Chronic kidney disease - Vitamin D status . Vitamin D replacement therapy. Glycemic control · Serum uric acid · Microalbuminuria

\begin{abstract}
Objective: To evaluate the relationship of vitamin D status and vitamin $D$ replacement therapy with glycemic control, serum uric acid (SUA) levels, and microalbuminuria (MAU) in patients with type 2 diabetes (T2DM) and chronic kidney disease (CKD). Subjects and Methods: A total of 1,463 patients with T2DM and CKD (aged 14-88 years), 927 females and 536 males, were included in this study. The serum data of 25-hydroxyvitamin D, i.e., $25(\mathrm{OH}) \mathrm{D}$, level, SUA, hemoglobin $(\mathrm{Hb})$ $A 1_{c}$, creatinine, estimated glomerular filtration rate, and urine albumin-to-creatinine ratio (UACR) were obtained from the medical records. The Mann-Whitney $U$ test, the $x^{2}$ test, the Mantel-Haenszel test, and linear regression models were used for data analysis. Results: Vitamin D deficiency and insufficiency were evident in 770 (52.0\%) and 357 (24.0\%) patients, respectively. Median $\mathrm{HbA}{ }_{\mathrm{c}}$ levels (7.3 [IQR 3.9] vs. 6.5 [IQR 2.3$] \% ; p<0.01)$ were significantly higher in patients deficient in vitamin $D$ than in those with a normal vitamin D status. A significantly low level of vitamin $D$ was
\end{abstract}

\begin{tabular}{ll}
\hline KARGER & ( 2016 S. Karger AG, Basel \\
$\begin{array}{l}\text { E-Mail karger@karger.com } \\
\text { www.karger.com/mpp }\end{array}$ & $\begin{array}{l}\text { This is an Open Access article licensed under the terms of the } \\
\text { Creative Commons Attribution-NonCommercial 3.0 Un- } \\
\text { ported license (CC BY-NC) (www.karger.com/OA-license), } \\
\text { applicable to the online version of the article only. Distribu- } \\
\text { tion permitted for non-commercial purposes only. }\end{array}$
\end{tabular}

noted with a high UACR $(\beta-0.01 ; 95 \% \mathrm{Cl}-0.01$ to -0.001 ; $p=0.017)$ and $\mathrm{HbA}_{\mathrm{c}}(\beta-1.1 ; 95 \% \mathrm{Cl}-1.6$ to $-0.6 ; p<0.001)$, but with low levels of SUA ( $\beta 1.3 ; 95 \% \mathrm{Cl} 0.5-2.2 ; p=0.002)$. Vitamin $D$ replacement was associated with a significantly low level of $\mathrm{HbA}_{\mathrm{c}}$ (7.4 [2.7] vs. 6.7 [1.9]\%; $p<0.001$ ]. Conclusion: In this study, there was a high prevalence of hypovitaminosis $D$ among T2DM patients with CKD, with a higher UACR, higher $\mathrm{HbA} 1_{c}$, and lower SUA being noted as playing a role in predicting a decrease in vitamin $D$ levels and potential benefits of vitamin $D$ replacement therapy on glycemic control in T2DM management.

(c) 2016 S. Karger AG, Basel

\section{Introduction}

In calcium-phosphate homeostasis and bone physiology, it is well known that vitamin D status is associated with a number of nonskeletal functions including glucose homeostasis, pathophysiology, and the progression of type 2 diabetes mellitus (T2DM) [1-3]. The serum 25-hydroxyvitamin $\mathrm{D}$, i.e., $25(\mathrm{OH}) \mathrm{D}$, level is considered to be the most stable and reliable indicator of vitamin $\mathrm{D}$ status $[4,5]$. It reflects vitamin D exposure based on the sum of endogenous synthesis and dietary intake from foods, for- 
tified products, and/or supplements [4, 5]. Most patients with T2DM have low 25(OH)D levels, while high levels are associated with a lower risk of incident diabetes $[6,7]$. Reduced nephron mass and/or 1-a hydroxylase enzyme activity has been shown to be associated with a decline in 1.25 dihydroxyvitamin D, i.e., $1.25(\mathrm{OH})_{2} \mathrm{D}$, levels in patients with chronic kidney disease (CKD) [8]. Hence, it has been suggested that renal status be considered in studies involving vitamin D status among T2DM patients [7].

Serum uric acid (SUA) has been shown to be associated with reduced levels of $1.25(\mathrm{OH})_{2} \mathrm{D}$ via the inhibition of 1- $\alpha$ hydroxylase activity $[9,10]$ as well as with microalbuminuria (MAU) [11]. This seems notable, since MAU is considered to be a biomarker for diagnosing diabetic kidney disease, and is a predictive factor for the progression to end-stage renal disease (ESRD) and increased cardiovascular risk among diabetic patients $[12,13]$.

Vitamin D supplementation for diabetic patients is of particular interest, with regard to its role in glucose hemostasis and thus its use as a potential cost-effective adjunct therapy in T2DM management $[14,15]$. However, data on the impact of maintaining an adequate vitamin $D$ status or supplementing with vitamin D on clinical outcomes in diabetic patients are inconsistent, probably reflecting the differences across studies in baseline vitamin D levels and replacement therapy dosage [14-16]. This study was therefore designed to evaluate the relationship of vitamin D status and vitamin D replacement therapy with glycemic control, SUA levels, and MAU in patients with T2DM and CKD.

\section{Subjects and Methods}

\section{Study Population}

A total of 1,463 patients with T2DM and CKD (age range 14-88 years), 927 females and 536 males, who had their serum 25(OH)D levels measured during follow-up at our diabetes outpatient clinic between January 2010 and January 2015, were included in this retrospective study. Exclusion criteria were an age of $<18$ years, pregnancy, a change in antidiabetic treatment during the study, and no data on concomitantly assessed vitamin D levels.

The study was conducted in full accordance with the local Good Clinical Practice guideline and current legislation, and permission was obtained from the Institutional Ethics Committee for the use of patient data for publication purposes.

\section{Study Assessments}

Data on patient demographics, laboratory parameters including analysis for $25(\mathrm{OH}) \mathrm{D}, \mathrm{SUA}, \mathrm{HbAl}_{\mathrm{c}}$, creatinine, estimated glomerular filtration rate (eGFR), and urine albumin-to-creatinine ratio (UACR) were obtained from medical records. Demographic characteristics and laboratory parameters were evaluated with respect to vitamin D status, while estimators of baseline vitamin D levels and the effect of vitamin D replacement therapy on the vitamin D, glycemic, and renal function parameters were also analyzed. Overall, 383 of 1,463 patients received vitamin D replacement therapy (75.000 units weekly). Pretreatment and posttreatment laboratory parameters were compared in these patients.

\section{Blood Biochemistry Analysis}

$25(\mathrm{OH}) \mathrm{D}$, creatinine, uric acid, $\mathrm{HbAl}_{\mathrm{c}}$, and hemogram were measured using a central laboratory biochemistry analyzer (ICT [ISE] Module of ARCHITECT c16000, Abbott Laboratories, Abbott Park, IL, USA). 25(OH)D levels were measured using high-performance liquid chromatography, and were classified as deficient $(<20$ $\mathrm{ng} / \mathrm{mL})$, insufficient $(20-30 \mathrm{ng} / \mathrm{mL})$ or optimal (>30 ng/mL) [17].

\section{Estimation of the Glomerular Filtration Rate}

The GFR was estimated according to the Modification of Diet in Renal Disease (MDRD) equation, which includes 4 variables: eGFR $\left(\mathrm{mL} / \mathrm{min} / 1.73 \mathrm{~m}^{2}\right)=175 \times(\text { serum creatinine })^{-1.154} \times$ $(\text { age })^{-0.203} \times(0.742$ if female) (conventional units) [18]. The patients were then classified into 5 CKD stages: stage 1 (eGFR $>90$ $\mathrm{mL} / \mathrm{min} / 1.73 \mathrm{~m}^{2}$ ); stage 2, mild CKD (eGFR 60-89 mL/min/ $\left.1.73 \mathrm{~m}^{2}\right)$; stage 3, moderate CKD (eGFR 30-59 mL/min $/ 1.73 \mathrm{~m}^{2}$ ); stage 4, severe CKD (eGFR $\left.15-29 \mathrm{~mL} / \mathrm{min} / 1.73 \mathrm{~m}^{2}\right)$; and stage 5 , end-stage CKD $\left(\mathrm{eGFR}<15 \mathrm{~mL} / \mathrm{min} / 1.73 \mathrm{~m}^{2}\right)$.

\section{Statistical Analysis}

Categorical variables were summarized as $n$ (\%) and continuous variables as median (IQR) due to nonnormal distribution patterns. Baseline vitamin D level groups were compared by means of the Mann-Whitney $U$ test for continuous variables, the $\chi^{2}$ test for nominal variables, and the Mantel-Haenszel test for ordinal variables. The estimators of baseline vitamin D levels were evaluated by using univariate and multivariate (adjusted for age and gender) linear regression models. The effect of vitamin D replacement therapy during follow-up was evaluated by the Wilcoxon or $\mathrm{McNe}$ mar-Bowker test depending on the variables. Type 1 error level was set at $5 \%$ and the Bonferroni adjustment for a type 1 error was used, where appropriate. Statistical analysis was conducted with Statistical Package for the Social Sciences software (v21.0, released 2012, IBM Corp., Armonk, NY, USA).

\section{Results}

Demographic Characteristics and Laboratory Findings The median (IQR) 25(OH)D level was 18.1 (15.5) ng/ $\mathrm{mL}$; vitamin $\mathrm{D}$ deficiency and insufficiency were evident in $770(52.6 \%)$ and $357(24.4 \%)$ patients, respectively. Stage 1-2 CKD was noted in 1,308 (91.9\%) patients. The median (IQR) level of $\mathrm{HbAl}_{\mathrm{c}}$ was $7.0(3.9 \%)$ and that of uric acid was $4.9(1.9) \mathrm{mg} / \mathrm{dL}$ in the overall study population (Table 1).

Vitamin D deficiency was associated with a significantly higher number of females $(n=527 ; 68.4 \%$ vs. $n=$ $197 ; 58.6 \% ; p=0.003$ ) and higher (median [IQR]) $\mathrm{HbAl}_{c}$ 
Table 1. Demographics, medical characteristics, and laboratory findings in the overall study population and according to baseline vitamin D status

\begin{tabular}{|c|c|c|c|c|c|c|}
\hline & $\begin{array}{l}\text { Deficiency } \\
(n=770)\end{array}$ & $p$ value & $\begin{array}{l}\text { Insufficiency } \\
(n=357)\end{array}$ & $p$ value & $\begin{array}{l}\text { Normal } \\
(n=336)\end{array}$ & $\begin{array}{l}\text { All patients } \\
(n=1,463)\end{array}$ \\
\hline \multicolumn{7}{|l|}{ Demographics } \\
\hline Female gender, $n$ & $527(68.4 \%)$ & $0.003^{\mathrm{b}}$ & $203(56.9 \%)$ & $1.000^{\mathrm{b}}$ & $197(58.6 \%)$ & $927(63.4 \%)$ \\
\hline \multicolumn{7}{|l|}{ Medical characteristics ${ }^{\mathrm{d}}$} \\
\hline Stage 2 & $239(31.9 \%)$ & & $112(31.9 \%)$ & & $106(32.9 \%)$ & $457(32.1 \%)$ \\
\hline Stage 3 & $59(7.9 \%)$ & & $25(7.1 \%)$ & & $23(7.1 \%)$ & $107(7.5 \%)$ \\
\hline Stage 4 & $6(0.8 \%)$ & & $1(0.3 \%)$ & & $0(0 \%)$ & $7(0.5 \%)$ \\
\hline Stage 5 & $0(0 \%)$ & & $1(0.3 \%)$ & & $0(0 \%)$ & $1(0.1 \%)$ \\
\hline \multicolumn{7}{|l|}{ Laboratory findings $\mathrm{s}^{\mathrm{d}}$} \\
\hline $\mathrm{HbAl}_{\mathrm{c}}, \%$ & $7.3(3.2)$ & $<0.001^{\mathrm{a}}$ & $6.8(3.0)$ & $0.305^{\mathrm{a}}$ & $6.5(2.3)$ & $7.0(3.9)$ \\
\hline \multicolumn{7}{|c|}{$\begin{array}{l}\text { Values are expressed as median }(\mathrm{IQR}) \text {, unless otherwise indicated. } \mathrm{CKD} \text {, chronic kidney disease; eGFR, estimated glomerular filtr } \\
\text { tion rate; } \mathrm{HbA} 1_{\mathrm{c}} \text {, glycated hemoglobin } \mathrm{A} 1_{c} ; \mathrm{SUA} \text {, serum uric acid; } \mathrm{UACR} \text {, urine albumin-to-creatinine ratio. Deficiency: a serum vitam } \\
\mathrm{D} \text { level }<20 \mathrm{ng} / \mathrm{mL} \text {; insufficiency: a serum vitamin } \mathrm{D} \text { level } \geq 20 \text { and }<30 \mathrm{ng} / \mathrm{mL} \text {; normal: a serum vitamin } \mathrm{D} \text { level } \geq 30 \mathrm{ng} / \mathrm{mL} \text {. } \\
\text { a Comparisons made by Mann-Whitney } \mathrm{U} \text { test and results adjusted by the Bonferroni method. } \\
{ }^{\mathrm{b}} \text { Comparisons made by } \chi^{2} \text { test and results adjusted by the Bonferroni method. } \\
{ }^{c} \text { Comparisons made by Mantel-Haenszel test and results adjusted by the Bonferroni method. } \\
{ }^{\mathrm{d}} \text { Data for some patients are missing, so results are based on available data. }\end{array}$} \\
\hline
\end{tabular}

levels $(7.3$ [3.2] vs. $6.5[2.3] \% ; p<0.01)$ compared with normal vitamin $\mathrm{D}$ status. Patients with vitamin $\mathrm{D}$ deficiency and insufficiency had significantly lower levels for SUA (4.7 [2.0] and 4.7 [1.7] vs. 5.1 [1.9] mg/dL, respectively; $p<0.001$ for each), and higher UACR (14.9 [42.9] and 15.2 [41.7] vs. 9.5 [19.6] mg/mmol; $p<0.01$ for each) when compared to patients with a normal vitamin D status (Table 1).

\section{Estimators of Baseline Vitamin D Levels}

Univariate linear regression analyses revealed lower vitamin D levels with higher UACR $(\beta-0.01 ; 95 \% \mathrm{CI}-0.01$ to $-0.001 ; p=0.017)$ and $\mathrm{HbAl}_{\mathrm{c}}(\beta-1.1 ; 95 \% \mathrm{CI}-1.6$ to -0.6 ; $p<0.001)$ levels but lower SUA $(\beta 1.3$; 95\% CI 0.5$2.2 ; p=0.002)$, even after adjusting for age and gender $(p=0.023, p=0.013$, and $p<0.001$, respectively; Table 2$)$.

\section{Effect of Vitamin D Replacement Therapy on}

Laboratory Findings

Among patients who had vitamin $\mathrm{D}$ replacement therapy $(n=383)$, after a median (IQR) 6.0 (5.0) months, there was a significant increase in (median [IQR]) 25(OH) D levels (from 18.1 [15.5] ng/mL pretreatment to 25.5 [19.1] ng/mL posttreatment; $p<0.001)$ and the percentage of patients with normal vitamin D status (from 19.8 to $37.1 \%$; $p<0.001$ ) (Table 3).

When compared to pretreatment values, posttreatment values showed a significant decrease (median [IQR]) in $\mathrm{HbAl}_{\mathrm{c}}$ (7.4 [2.7] vs. 6.7 [1.9]\%; $\left.p<0.001\right)$ and eGFR (92.3 [30.3] vs. 91.4 [30.4] $\mathrm{mL} / \mathrm{min} / 1.73 \mathrm{~m}^{2} ; p<$ 0.001). Analysis of data adjusted for follow-up duration also revealed a significant decrease in mean $(95 \% \mathrm{CI})$ $\mathrm{HbA1} 1_{\mathrm{c}}$ levels from baseline to follow-up $(7.8[7.6-8.0]$ vs. $7.1[6.9-7.2] \% ; p<0.001$ ) (Table 3).

\section{Discussion}

Our findings in a cohort of patients with T2DM and CKD revealed a high prevalence (approx. 70\%) of hypovitaminosis $\mathrm{D}$, particularly among females, in cases of vitamin $\mathrm{D}$ deficiency. Higher levels of $\mathrm{HbA} 1_{\mathrm{c}}$ and UACR, 
Table 2. Estimators of baseline vitamin D levels

\begin{tabular}{|c|c|c|c|c|}
\hline & \multicolumn{2}{|l|}{ Univariate } & \multicolumn{2}{|l|}{ Adjusted $^{\mathrm{a}}$} \\
\hline & $\beta(95 \% \mathrm{CI})$ & $p$ value & $\beta(95 \% \mathrm{CI})$ & $p$ value \\
\hline Serum creatinine, $\mathrm{mg} / \mathrm{dL}$ & $1.3(-2.9$ to 5.5$)$ & 0.541 & $-1.2(-5.9$ to 3.6$)$ & 0.629 \\
\hline $\mathrm{eGFR}, \mathrm{mL} / \mathrm{min} / 1.73 \mathrm{~m}^{2}$ & $-0.03(-0.07$ to 0.02$)$ & 0.212 & $-0.02(-0.07$ to 0.03$)$ & 0.372 \\
\hline UACR, mg/mmol & $-0.01(-0.01$ to -0.001$)$ & 0.017 & $-0.01(-0.01$ to -0.001$)$ & 0.023 \\
\hline SUA, mg/dL & $1.3(0.5-2.2)$ & 0.002 & $1.1(0.2-2.0)$ & 0.013 \\
\hline $\mathrm{HbAl}_{c}, \%$ & $-1.1(-1.6$ to -0.6$)$ & $<0.001$ & $-1.2(-1.7$ to -0.8$)$ & $<0.001$ \\
\hline
\end{tabular}

Data on some patients are missing, so the results are based on the available data. $\beta$, linear regression coefficient; eGFR, estimated glomerular filtration rate; $\mathrm{HbA} 1_{c}$, glycated hemoglobin $\mathrm{A} 1_{c} ; \mathrm{SUA}$, serum uric acid; UACR, urine albumin-to-creatinine ratio.

a Results of linear regression model which was adjusted for patients' age and gender.

Table 3. Effect of vitamin D replacement therapy on renal function and glycemic parameters and vitamin D status

\begin{tabular}{|c|c|c|c|c|}
\hline Parameters & Patients, $n$ & At baseline & After treatment & $p$ value $^{\mathrm{a}}$ \\
\hline \multicolumn{5}{|l|}{ Renal function ${ }^{\mathrm{b}}$} \\
\hline Serum vitamin $\mathrm{D}, \mathrm{ng} / \mathrm{mL}$ & 383 & $18.1(15.5)$ & $25.5(19.1)$ & $<0.001$ \\
\hline Serum creatinine, $\mathrm{mg} / \mathrm{dL}$ & 368 & $0.8(0.2)$ & $0.8(0.2)$ & 0.054 \\
\hline $\mathrm{eGFR}, \mathrm{mL} / \mathrm{min} / 1.73 \mathrm{~m}^{2}$ & 368 & $92.3(30.3)$ & $91.4(30.4)$ & $<0.001$ \\
\hline SUA, mg/dL & 72 & $4.8(2.0)$ & $5.0(1.5)$ & 0.470 \\
\hline \multirow{2}{*}{$\begin{array}{l}\mathrm{HbA} 1_{c}, \%^{\mathrm{b}} \\
\quad \text { Mean }(95 \% \mathrm{CI})\end{array}$} & \multirow[t]{2}{*}{373} & $7.4(2.7)$ & $6.7(1.9)$ & $<0.001$ \\
\hline & & $7.8(7.6-8.0)$ & $7.1(6.9-7.2)$ & $<0.001$ \\
\hline \multicolumn{5}{|l|}{ Vitamin D status, $n(\%)$} \\
\hline Deficiency & & $224(58.5)$ & $140(36.6)$ & $<0.001$ \\
\hline Insufficiency & & $83(21.7)$ & $101(26.4)$ & \\
\hline Normal & & $76(19.8)$ & $142(37.1)$ & \\
\hline
\end{tabular}

eGFR, estimated glomerular filtration rate; $\mathrm{HbA}_{1}$, glycated hemoglobin $\mathrm{A} 1_{\mathrm{c}}$; SUA, serum uric acid; UACR, urine albumin-to-creatinine ratio.

${ }^{\text {a }}$ Results of comparison to normal vitamin D group.

${ }^{\mathrm{b}}$ Median (IQR).

and lower levels of SUA were shown to predict lower vitamin D levels. Vitamin D replacement revealed an increase in patients with normal vitamin $\mathrm{D}$ status, along with a significant decrease in $\mathrm{HbA1}_{\mathrm{c}}$ levels.

The high $76.0 \%$ prevalence of hypovitaminosis $\mathrm{D}$ in our cohort, particularly among females, in cases of vitamin D deficiency, was similar to the previously published data indicating, overall, a $73.0 \%$ prevalence of hypovitaminosis D (higher in females) among Turkish T2DM patients $[19,20]$.

This lower level of 25(OH)D among diabetic patients and higher $\mathrm{HbAl} 1_{\mathrm{c}}$ in cases of hypovitaminosis $\mathrm{D}$ than with vitamin $\mathrm{D}$ sufficiency was also reported in other studies on diabetic patients with various stages of CKD $[7,19,21,22]$. Our findings also revealed a significant role of higher $\mathrm{HbA} 1_{\mathrm{c}}$ in predicting a decrease in vitamin $\mathrm{D}$ levels, in agreement with previous studies [7, 23, 24].

In this cohort, vitamin $D$ replacement therapy enabled a significant improvement in $\mathrm{HbA} 1_{\mathrm{c}}$ levels. In an analysis of insulin-naïve T2DM patients with vitamin D deficiency who received vitamin D supplementation, all patients were reported to achieve serum levels of $25(\mathrm{OH}) \mathrm{D}>20$ $\mathrm{ng} / \mathrm{mL}$, along with a significant reduction in fasting blood glucose, but nonsignificant reductions in $\mathrm{HbAl}_{\mathrm{c}}$, fasting insulin, and HOMA-IR [16]. 
In this cohort, the increase in median $25(\mathrm{OH}) \mathrm{D}$ level, from 18.1 to $25.5 \mathrm{ng} / \mathrm{mL}$, along with an increase in the rate of normal vitamin D status, from 19.8 to $37.1 \%$, due to the vitamin D replacement, could have produced extraskeletal benefits of vitamin D as suggested previously [25].

The significant improvement in $\mathrm{HbA} 1_{\mathrm{c}}$ levels after vitamin D replacement therapy that we observed emphasizes the association of vitamin D levels with glucose hemostasis in T2DM, and the potential therapeutic implications of this association in achieving improved glycemic control in T2DM management [21]. Similar to our findings, the likely benefit of vitamin D substitution for a better T2DM prognosis was suggested in a 15-year longitudinal study among T2DM patients [26]. Clinical trials, however, have revealed inconsistent findings on the impact of maintaining adequate vitamin $\mathrm{D}$ status and/or high-dose vitamin replacement on long-term glycemic control in T2DM patients [14-16, 27]. Thus, the need for validation by further large-scale, cross-sectional, and interventional clinical studies is emphasized [15].

Given that renal status is a covariant influencing vitamin D status [7], it seems worth noting that the majority of our patients had stage 1-2 CKD and no difference was noted in the CKD stage of the patients with respect to vitamin D status.

A decrease in SUA was amongst the predictors of hypovitaminosis $\mathrm{D}$ in our study. This seems to contrast with past studies that indicated an association between hyperuricemia and hypovitaminosis $\mathrm{D}$ in gout, diabetes, and CKD patient populations $[10,19,28]$. In addition, no association was shown between reduced $25(\mathrm{OH}) \mathrm{D}$ levels and elevated SUA in premenopausal women, regardless of concomitant T2DM and hypertension [29]. This seems to indicate the likelihood of a multifaceted pathogenesis of the interaction between vitamin D status and SUA, with the contribution of several endocrine factors $[9,30]$.

In this cohort, higher UACR was shown to predict a decrease in vitamin $\mathrm{D}$ levels. This seems to support the linear relation between vitamin $\mathrm{D}$ deficiency and progression of MAU reported in T2DM patients [13, 27], while also emphasizing the potential benefit of the normalization of vitamin D levels in the reduction of renal and cardiovascular risks associated with MAU in these patients $[12,13]$.

Certain limitations to this study include its retrospective, single-center design and thus an inability to generalize our findings to the overall diabetic population, the lack of data on parathyroid hormone levels and seasonal changes in vitamin D levels, and also the fact that there was no standard duration of vitamin $\mathrm{D}$ treatment.

\section{Conclusion}

Our findings in a cohort of patients with T2DM and CKD revealed a high prevalence (70\%) of hypovitaminosis D, particularly among females, in cases of vitamin D deficiency. Higher UACR, higher $\mathrm{HbA} 1_{c}$, and lower SUA were shown to predict a decrease in vitamin $\mathrm{D}$ levels. Vitamin D replacement therapy had a beneficial effect on glucose hemostasis via a significant reduction in $\mathrm{HbA} 1_{c}$; this emphasizes the potential therapeutic implications of vitamin $\mathrm{D}$ supplementation as a promising preventative and therapeutic agent for improved glycemic control among T2DM patients with CKD. We recommend an evaluation of the relationship between hypovitaminosis $\mathrm{D}$ and SUA and of the impact of longer-term vitamin D replacement therapy on glycemic control and renal function among diabetic patients in a large-scale clinical study.

\section{Disclosure Statement}

There were no conflicts of interest.

\section{References}

1 Matyjaszek-Matuszek B, Lenart-Lipińska M, Woźniakowska E: Clinical implications of vitamin D deficiency. Prz Menopauzalny 2015; 14:75-81.

2 Adams JS, Hewison M: Update in vitamin D. J Clin Endocrinol Metab 2010;95:471-478.

3 Thomas GN, ó Hartaigh B, Bosch JA, et al: Vitamin D levels predict all-cause and cardiovascular disease mortality in subjects with the metabolic syndrome: the Ludwigshafen Risk and Cardiovascular Health (LURIC) Study. Diabetes Care 2012;35:1158-1164.

4 Ross AC, Manson JE, Abrams SA, et al: The 2011 report on dietary reference intakes for calcium and vitamin D from the Institute of Medicine: what clinicians need to know. J Clin Endocrinol Metab 2011;96:53-58.

5 Thacher TD, Clarke BL: Vitamin D insufficiency. Mayo Clin Proc 2011;86:50-60; review.
6 Pittas AG, Nelson J, Mitri J, et al: Plasma 25-hydroxyvitamin $\mathrm{D}$ and progression to diabetes in patients at risk for diabetes: an ancillary analysis in the Diabetes Prevention Program. Diabetes Care 2012;35:565-373.

7 Kajbaf F, Mentaverri R, Diouf M, et al: The association between 25-hydroxyvitamin $\mathrm{D}$ and hemoglobin $A 1_{c}$ levels in patients with type 2 diabetes and stage 1-5 chronic kidney disease. Int J Endocrinol 2014;2014:142468. 
8 Levin A, Bakris GL, Molitch M, et al: Prevalence of abnormal serum vitamin D, PTH, calcium, and phosphorus in patients with chronic kidney disease: results of the study to evaluate early kidney disease. Kidney Int 2007;71: 31-38.

9 Chen W, Roncal-Jimenez C, Lanaspa M, et al: Uric acid suppresses 1 alpha hydroxylase in vitro and in vivo. Metabolism 2014;63:150160.

10 Vanholder R, Patel S, Hsu CH: Effect of uric acid on plasma levels of $1,25(\mathrm{OH})_{2} \mathrm{D}$ in renal failure. J Am Soc Nephrol 1993;4:1035-1038.

11 Hayashino Y, Okamura S, Tsujii S, et al: Association of serum uric acid levels with the risk of development or progression of albuminuria among Japanese patients with type 2 diabetes: a prospective cohort study (Diabetes Distress and Care Registry at Tenri [DDCRT 10]). Acta Diabetol 2016;53:599-607.

12 Kitada M, Kanasaki K, Koya D: Clinical therapeutic strategies for early stage of diabetic kidney disease. World J Diabetes 2014;5:342356.

13 Bonakdaran S, Varasteh AR: Correlation between serum 25 hydroxy vitamin $\mathrm{D}_{3}$ and laboratory risk markers of cardiovascular diseases in type 2 diabetic patients. Saudi Med J 2009; 30:509-514.

14 Nasri H, Behradmanesh S, Maghsoudi AR, et al: Efficacy of supplementary vitamin D on improvement of glycemic parameters in patients with type 2 diabetes mellitus; a randomized double blind clinical trial. J Renal Inj Prev 2013;3:31-34.
15 Leung PS: The potential protective action of vitamin $\mathrm{D}$ in hepatic insulin resistance and pancreatic islet dysfunction in type 2 diabetes mellitus. Nutrients 2016;8:E147.

16 Calvo-Romero JM, Ramiro-Lozano JM: Metabolic effects of supplementation with vitamin $\mathrm{D}$ in type 2 diabetic patients with vitamin D deficiency. Diabetes Metab Syndr 2015;10: 72-74.

17 Holick MF: Vitamin D deficiency. N Engl J Med 2007;357:266-281.

18 Levey AS, Stevens LA, Schmid CH, et al: A new equation to estimate glomerular filtration rate. Ann Intern Med 2009;150:604-612.

19 Yilmaz H, Kaya M, Sahin M, et al: Is vitamin $\mathrm{D}$ status a predictor of glycaemic regulation and cardiac complication in type 2 diabetes mellitus patients? Diabetes Metab Syndr 2012;6:28-31.

20 Isaia G, Giorgino R, Adami S: High prevalence of hypovitaminosis D in a female type 2 diabetic population. Diabetes Care 2001;24: 1496.

21 Kostoglou-Athanassiou I, Athanassiou P, Gkountouvas A, et al: Vitamin D and glycemic control in diabetes mellitus type 2 . Ther Adv Endocrinol Metab 2013;4:122-128.

22 Pilz S, van den Hurk K, Nijpels G, et al: Vitamin $\mathrm{D}$ status, incident diabetes and prospective changes in glucose metabolism in older subjects: the Hoorn study. Nutr Metab Cardiovasc Dis 2012;22:883-889.
23 Zoppini G, Galletti A, Targher G, et al: Glycated haemoglobin is inversely related to serum vitamin $\mathrm{D}$ levels in type 2 diabetic patients. PLoS One 2013;8:e82733.

24 Soric MM, Renner ET, Smith SR: Effect of daily vitamin $\mathrm{D}$ supplementation on $\mathrm{HbA} 1_{\mathrm{c}}$ in patients with uncontrolled type 2 diabetes mellitus: a pilot study. J Diabetes 2012;4:104105 .

25 Hossein-nezhad A, Holick MF: Vitamin D for health: a global perspective. Mayo Clin Proc 2013;88:720-755.

26 Joergensen C, Gall MA, Schmedes A, et al: Vitamin $\mathrm{D}$ levels and mortality in type 2 diabetes. Diabetes Care 2010;33:2238-2243.

27 Shehab D, Al-Jarallah K, Abdella N, et al: Prospective evaluation of the effect of short-term oral vitamin D supplementation onperipheral neuropathy in type 2 diabetes mellitus. Med Princ Pract 2015;24:250-256.

28 Takahashi S, Yamamoto T, Moriwaki Y, et al: Decreased serum concentrations of $1,25(\mathrm{OH})_{2}$-vitamin $\mathrm{D}_{3}$ in patients with gout. Metabolism 1998;47:336-338.

29 Peng H, Li H, Li C, et al: Association between vitamin D insufficiency and elevated serum uric acid among middle-aged and elderly Chinese Han women. PLoS One 2013;8:e61159.

30 Hui JY, Choi JW, Mount DB, et al: The independent association between parathyroid hormone levels and hyperuricemia: a national population study. Arthritis Res Ther 2012; 14:R56. 